\title{
Prevalence and awareness of Anabolic Androgenic Steroids (AAS) among gymnasts in the western province of Riyadh, Saudi Arabia
}

Khaled Abdullah Al Bishi ${ }^{1}$, Ayman Afify ${ }^{2}$

${ }^{1}$ M.B.B.S, Resident in Saudi Board of Family Medicine, Prince Sultan Military Medical City, Riyadh, Saudi Arabia

${ }^{2}$ Consultant Family Medicine and EBM, MRCGP. Educ. Certify, Dundee University, United Kingdom

\section{Type of article: Original}

\begin{abstract}
Background: Anabolic Androgenic Steroids (AAS) are synthetic derivatives of the male sex hormone (testosterone) that are increasingly used by athletes as performance enhancing drugs to increase muscle mass and strength. Multiple health adverse effects may be caused by its non-medical use. Several international and regional studies showed the high prevalence of AAS usage and low level of awareness of it among different populations.

Objective: To estimate the prevalence of AAS and to determine the level of awareness toward it among gymnasts in the western province of Riyadh.

Methods: This cross-sectional survey was conducted using a self-administered questionnaire distributed on 400 male gymnasts from 10 different fitness centers which have been chosen randomly from 23 centers in the western province of Riyadh city (Kingdom of Saudi Arabia) during 2016. Data analysis was performed by SPSS version 21, using descriptive statistics and Chi-square test.

Results: Among the 400 gymnasts who participated in the survey, a total of $n=363$ questionnaires were received completed. Of the responders, $(n=89)$ were AAS users with a percentage $24.50 \%$. The testosterone was the most commonly used type followed by Methandrostenolone then Stanozolol. The major sources for obtaining AAS were online shopping (45\%) and gym-coach (22.5\%). Regarding awareness, $74 \%$ of AAS users had an inadequate perception about AAS concept versus $55 \%$ of non-users with no significant difference $(\mathrm{p}=0.076)$. In addition, $82 \%$ of AAS users and $83 \%$ of non-users had inadequate knowledge of AAS adverse effects with no significant difference between the two categories $(\mathrm{p}=0.087)$.

Conclusion: The usage of AAS is high amongst gymnasts in the western province of Riyadh city considering they are prohibited. The level of awareness toward AAS is low among most gymnasts. We recommend for educational programs to be established in order to increase public awareness, in addition to a tightening of control by the responsible authorities over the sources of AAS procurement.

Keywords: Gymnastics, Androgens, Synthetic, AAS, Substance abuse, Performance enhancing drugs
\end{abstract}

\section{Introduction}

\subsection{Background}

Anabolic Androgenic Steroids (AAS) are synthetic preparations of the male sex hormone testosterone (1). They are classified as steroids due to their inclusion of a steroid ring in their composition. Anabolic Androgenic Steroids have dual action; an androgenic action that produces male secondary sexual characteristics, and anabolic action that maintains muscle mass by maintaining nitrogen balance. They have been modified to be anabolic more than androgenic. However, the complete dissociation between the two actions is not available yet. Medically used as hormone replacement therapy to treat conditions such as; protein-calories malnutrition associated with weight loss, primary and secondary hypogonadism and HIV wasting syndrome (2). Since 1950, AAS began to be used in supraphysiologic doses as performance enhancing drugs (PED) by elite athletes to increase their muscle mass and

\section{Corresponding author:}

Dr. Khaled Abdullah Al Bishi, Prince Sultan Military Medical City, Riyadh, Saudi Arabia.

Tel: +966114326228, E-mail: dr-ksa1@hotmail.com

Received: August 06, 2017, Accepted: October 22, 2017, Published: December 2017

iThenticate screening: October 30, 2017, English editing: November 08, 2017, Quality control: November 10, 2017

This article has been reviewed / commented by three experts

(C) 2017 The Authors. This is an open access article under the terms of the Creative Commons Attribution-NonCommercialNoDerivs License, which permits use and distribution in any medium, provided the original work is properly cited, the use is non-commercial and no modifications or adaptations are made. 
strength. Currently, their usage is spread worldwide even among the general public (3). As a consequence of this widespread use, many side effects are reported by the users such as the presence of acne vulgaris, increased sexual drive, increased body hair and inducement of aggressive behavior (4). Also, AAS is considered as the leading cause for cardiovascular, hepatic, endocrine, and reproductive dysfunctions $(2,5)$, where they cause ventricular arrhythmia, dyslipidemia, elevated blood pressure, hepatotoxicity, glucose intolerance, gynecomastia and spermatogenic dysfunction. Most of these effects are dose dependent and reversible after quitting the used substance. Multiple studies have documented that the withdrawal symptoms of AAS include depression and suicidal ideation. Therefore, they are considered to cause addiction. AAS have been prepared from testosterone in several preparations, some in the form of oral and some in the form of parenteral administrations. Most of them are derived from 3 parenteral compounds testosterone, 19-nortestosterone, and dihydrotestosterone. The common preparations are Testosterone-esters, testosterone derivatives, Methandrostenolone, Nandrolone, Trenbolone, Oxandrolone and Stanozolol (2). AAS users usually take them in different ways which they believe are preventing the side effects and maximizing their actions. One common practice is the cyclic method by taking doses for a period, stopping for a time, and then restarting. There is also the stacking method by combining two or more different types of steroids, and the pyramiding method by a gradual increase of the dose until reaching a peak dose, then gradually tapering off. However, no scientific evidence shows that these practices are reducing the adverse effect of AAS (6). The world anti-doping agency (WADA) was established in 1990 as an independent international agency. Its responsibility includes research, education, development of anti-doping capacities, and the production of a list of prohibited substances. AAS is addressed as the first substance on the prohibited list at all times in and out of competition (7).

\subsection{Literature Review and Rationale of the study}

Prevalence of AAS abuse among athletes in the America has been estimated around 20\% (9). While in South Wales in the UK, $70 \%$ of gymnasts reported AAS use (10). A systematic review done in Brazil showed that the prevalence of AAS abuse is between $2.1 \%$ and $31.6 \%$ and varies according to region (11). In the Netherlands, the prevalence of AAS usage is estimated at 20,000 persons, particularly in gym visitors (12). Regionally, $22.7 \%$ of fitness center attendees in Kuwait are using AAS (13). In the United Arab Emirates, the prevalence of AAS is assessed at 22\% of gymnasts (14). In Jordan, the percentage of AAS usage among athletes has been a reported $26 \%$ (15). In western Iran, the frequency of AAS abuse is estimated at $28.8 \%$ of bodybuilders (16). Several studies have been conducted to estimate the level of awareness toward AAS. A survey done in Sweden showed that fewer male adolescent users believed AAS to be harmful (17). A study conducted on male medical students in Iran showed a low rate of awareness level (18). Fifty percent of AAS users in Kuwait have no adequate awareness about the side effects of AAS and no significant difference between them and non-users in knowledge of AAS (13). Locally, in Saudi Arabia, three related research studies have been done in one year (2016). The first survey ever done was by Alghobain, and showed that prevalence of the prohibited doping substance among Saudi sports players is 4.3\% (19). The second study is unpublished, and done by Alromaih, and it revealed that the prevalence of performance enhancing drugs among Riyadh fitness center attendees is $23.17 \%$, of which, $28.2 \%$ is of the Anabolic Androgenic Steroid (20). The third study was done by Jabari M. et al., and showed that the prevalence of anabolic androgenic steroid use amongst athletes in Riyadh is $30.5 \%$ and revealed that $40 \%$ among non-users had proper knowledge, while all the AAS users had inadequate knowledge about the adverse effect of AAS (21). In light of the above, we found the importance of this topic and its recent spread in Saudi Arabia as well as its adverse health effects will cost the youth power of the country. So, we have done this study to ascertain the prevalence of Anabolic Androgenic Steroids (AAS) in the western province of Riyadh. Moreover, to research the associating factors leading to its usage, the most common types and sources of gaining it as well as to measure the awareness of it. We look forward to the results of this study to help reduce the spread of steroids and mitigate the health effects of their use, in addition to providing information on the use of AAS in terms of types and sources and ways of how to obtain them, based on the above solutions, can be developed.

\subsection{Objectives}

The objectives of this research were: 1) to measure the prevalence of AAS use among gymnasts in the western province of Riyadh city, 2) to determine the level of awareness of AAS use among gymnasts in the western province of Riyadh city, and 3) to determine the associating factors that are affecting the prevalence and awareness of AAS among gymnasts in the western province of Riyadh city. 


\section{Material and Methods}

\subsection{Study design}

This cross-sectional survey was conducted on male gymnasts visiting fitness centers in the western province of Riyadh city (capital of Saudi Arabia) during 2016. The western province has been chosen randomly after dividing Riyadh into five provinces (northern, southern, western, eastern and central), and its gyms were the area of study.

\subsection{Participants}

\subsubsection{Selection criteria}

Inclusion criteria were being male, older than 18 years and attendees of the selected gyms. Exclusion criteria were being younger than 18 years, female, professional athletes or repeated registration in more than one center of the centers included in our study.

\subsubsection{Target Population:}

A list of sports centers in the western province of Riyadh including fitness centers has been derived from the website of the High Commission of the development of Riyadh. Moreover, the approximate numbers of their attendees were taken from the administration of each center by phone.

\subsubsection{Study population}

Three of the 26 listed centers were excluded because their activity differs to our study target. Resulting in 23 centers with a total of approximately 2,040 gymnasts.

\subsection{Sampling}

The sample size was determined to be 384 . Then it was corrected to be convenient to finite population $\leqslant 20,000$. Two-stage sampling was used. In the first stage, ten fitness centers were selected by simple random sampling technique using the computer-generated list of random numbers (random.org). In the second stage, stratified systematic sampling technique was used to distribute the sample size $(n=400)$ on the selected centers proportionally to total study population, then every 3rd gymnast leaving the centers were included in this survey as a participant. Visiting the chosen fitness centers was scheduled on different days and times for each center to guarantee the involvement of the most representative sample.

\subsection{Measures and Instruments}

Self-administrated questionnaires of one paper in Arabic and English were distributed to the participants in the form of Quick Response code (QR code) to link into online internet survey (Survey Monkey website) by using a mobile camera. The questionnaire was built from several literature reviews. Its validity was done at two stages, face validity by untrained judges, then content validity by three specialized consultants. After that, test- retest reliability was done with correlation coefficient $(\mathrm{r}=78)$. The questionnaire consisted of an introduction page and five parts. The introduction page contained the title of study, instructions, informed consent and researcher contacts. Part 1 of the questionnaire contained the sociodemographic characteristics questions. Part 2 contained the type and reason for using the gym. Part 3 contained the practice of anabolic androgenic steroid use, to estimate the prevalence and practice of anabolic androgenic steroid. Part 4 contained assessment quiz of perception toward AAS concept, consisting of four questions with choices (true, false, I do not know). By using a scoring system (true $=1$ score, false $=0$, I don't know $=0$ ), responders with a score $=4$ are considered with complete perception, and those with score 2-3 are considered with partial perception, while those with score $0-1$ are considered with inadequate perception. Part 5 contained an assessment quiz of knowledge about potential adverse effects of AAS consisting of 8 questions with choices (true, false, I do not know). By using the previous scoring system, the responders with a score $=6-8$ are considered having appropriate knowledge, and those with a 3-5 score were considered to have partial knowledge, and with a 0-2 score were considered to have inadequate knowledge.

\subsection{Data analysis}

Data analysis was performed using IBMC SPSS $\odot$ Statistics version 22 (IBMC Corp., Armonk, NY, USA). Frequency and percentage distributions were calculated. Chi-square test was used to test the differences between AAS users and non-users. The p-value less than 0.05 was considered to be statistically significant.

\subsection{Ethical consideration}

Approval for this study was obtained from the research ethics committee at Prince Sultan Military Medical City (Reg. \# HAP-01-R-015) project NO. 812 Date of approval 09 May 2016. Informed consent from the participant was 
ensured before filling the questionnaire. Also, confidentiality, anonymity and voluntary participation were granted for the participants. Unfortunately, multiple attempts to get official permission from gym centers for data collection had failed. So, the questionnaires were distributed at the gym's parking lots after clarification that they were not within the ownership of the gyms.

\section{Results}

\subsection{Sociodemographic and general findings}

A total of 400 questionnaires were distributed to participant gymnasts, and $n=363$ questionnaires were returned completely with a response rate of $90.75 \%$. Of the responders, $(n=89)$ were current AAS users with a percentage of $24.50 \%$, while ( $\mathrm{n}=274)$ were AAS-non-users with a percentage of $75.5 \%$. The age of AAS users ranged from 18 to 49 years with the majority (54\%) belonging to the age group of 26-33 years, followed by the age groups 18-25 (24\%) and 34-41 (19\%). However, $82 \%$ of AAS users were Saudi citizens, more than half of non-Saudi participants (59\%) were users. Most of the AAS users reported having a bachelor degree (51.69\%), while of AAS-non-users, $(74.45 \%)$ had secondary school degree. Other demographic characters of gymnasts were divided according to AAS usage status for comparison, as shown in (Table 1).

Table 1. Sociodemographic characteristics of AAS users in comparison with non-users.

\begin{tabular}{|c|c|c|c|c|}
\hline \multirow{2}{*}{\multicolumn{2}{|c|}{ Variables }} & \multicolumn{2}{|c|}{ AAS users (n) } & \multirow[t]{2}{*}{ p-value } \\
\hline & & Yes & No & \\
\hline \multirow{5}{*}{ Age (year) } & $18-25$ & 21 & 193 & \multirow{5}{*}{$<0.001$} \\
\hline & $26-33$ & 48 & 48 & \\
\hline & $34-41$ & 17 & 24 & \\
\hline & $42-49$ & 3 & 5 & \\
\hline & 50 or above & 0 & 4 & \\
\hline \multirow[t]{2}{*}{ Nationality } & Saudi & 73 & 263 & \multirow[t]{2}{*}{0.005} \\
\hline & Others & 16 & 11 & \\
\hline \multirow[t]{5}{*}{ Level of education } & Master or Ph.D. & 14 & 6 & \multirow[t]{5}{*}{$<0.001$} \\
\hline & Completed University & 46 & 47 & \\
\hline & Completed Secondary school & 29 & 204 & \\
\hline & Completed Intermediate school & 0 & 15 & \\
\hline & Completed Primary school & 0 & 2 & \\
\hline \multirow{4}{*}{ Marital status } & Single & 28 & 175 & \multirow{4}{*}{$<0.001$} \\
\hline & Married & 53 & 86 & \\
\hline & Divorced & 8 & 10 & \\
\hline & Widow & 0 & 3 & \\
\hline \multirow{6}{*}{ Occupation } & Governmental employee & 45 & 63 & \multirow[t]{6}{*}{$<0.001$} \\
\hline & Private employee & 20 & 51 & \\
\hline & Military & 12 & 52 & \\
\hline & Student & 9 & 94 & \\
\hline & Unemployed & 3 & 9 & \\
\hline & Retired & 0 & 5 & \\
\hline \multirow{5}{*}{ Monthly income (SAR) } & $<3,000$ & 10 & 90 & \multirow[t]{5}{*}{$<0.001$} \\
\hline & $3,000-6,000$ & 6 & 61 & \\
\hline & $6,000-9,000$ & 21 & 79 & \\
\hline & $9,000-12,000$ & 39 & 37 & \\
\hline & $\geq 12,000$ & 13 & 7 & \\
\hline
\end{tabular}

\subsection{Type of Gym use}

Most of the participants were using the gym for six months or more by an average of 2 to 5 days per week with no significant difference between AAS users and non-users. Most of the users (67.4\%) were using the gym for 1 to 2 hours per visit. Also, $85.4 \%$ of users were attending the gym for body building target versus $16.8 \%$ of non-users $(\mathrm{p}<0.001)$ (Table 2). 


\subsection{Practice of AAS users}

Testosterone was found to be the most commonly used AAS among gymnasts (34.8\%), followed by Methandrostenolone (14.6\%) then Stanozolol (11.2\%). The other common used drugs were Nandrolone (10.1\%), Boldenone (10.1\%), Oxandrolone (7.8\%), Drostanolone (4.5\%), 19-Norandrostendione (3.3\%), 19-Norandrostendiol $(1.1 \%)$, Trenbolone $(1.1 \%)$, and Metonolone (1.1\%). The major source for obtaining AAS was online shopping (45\%), gym-coach (22.5\%) comes to be the second major source for AAS, followed by black market (anonymous persons) $(12.3 \%)$, friends $(9 \%)$, pharmacists $(6.7 \%)$, fitness stores $(3.3 \%)$, and physicians $(1.1 \%)$. The predominant reason for AAS usage among users were improving body appearance $(63 \%)$ and increasing its power and strength $(28 \%)$ but the less common reasons were participating in competitions (4.5\%), improving sexual drive (3.3\%), and for medical purposes $(1.1 \%)$. Injectable AAS was the most common practice of use $(56.1 \%)$. Both oral and injectable forms of AAS were used in approximately equal frequency (23.6\%). Duration of using AAS was 6-12 months for $41.5 \%$ of users, followed by $1-2$ years $(24.7 \%), 1-6$ months $(13.5 \%)$, more than 2 years $(13.5 \%)$, and less than 1 month $(6.7 \%)$.

\subsection{Perception assessment of AAS concept}

The majority of users were aware of AAS anabolic effects such as increased muscle size and its usage for body building versus a minority of non-users $(\mathrm{p}=0.005)$. Most of the participant gymnasts were unaware that AAS is a doping substance and its usage without medical cause is illegal in Saudi Arabia with no significant difference between users and non-users. Overall, among AAS users, 74\% had an inadequate perception about AAS concept while it was $55 \%$ among non-users.

\subsection{Knowledge assessment of AAS Adverse Effects}

When knowledge about potential adverse effects of AAS was examined, we found that $82 \%$ of users had inadequate knowledge and only $2.2 \%$ of them had appropriate knowledge, while $83 \%$ of non-AAS users had inadequate knowledge of its adverse effect, and only $7.6 \%$ of them had appropriate knowledge with no significant difference between the two categories.

Table 2. Type and reason of gym use among AAS users and non-users

\begin{tabular}{|c|c|c|c|c|}
\hline \multirow{2}{*}{\multicolumn{2}{|c|}{ Variables }} & \multicolumn{2}{|c|}{ AAS users (n) } & \multirow[t]{2}{*}{ p-value } \\
\hline & & Yes & No & \\
\hline \multirow[t]{5}{*}{ Gym use duration } & $<1$ month & 1 & 11 & \multirow[t]{5}{*}{ NS* } \\
\hline & 1-6 months & 1 & 26 & \\
\hline & 6-12 months & 27 & 92 & \\
\hline & $1-2$ years & 25 & 99 & \\
\hline & $\geq 2$ years & 35 & 46 & \\
\hline \multirow[t]{4}{*}{ No. of days visiting gym per week } & 1 & 3 & 17 & \multirow[t]{4}{*}{ NS* } \\
\hline & $2-3$ & 23 & 124 & \\
\hline & $4-5$ & 52 & 115 & \\
\hline & $6-7$ & 11 & 18 & \\
\hline \multirow[t]{4}{*}{ Duration of gym use per visit } & $<30$ minutes & $1(0.3 \%)$ & 12 & \multirow[t]{4}{*}{ NS* } \\
\hline & 30-60 minutes & $17(4.7 \%)$ & 135 & \\
\hline & $1-2$ hours & $60(16.5 \%)$ & 112 & \\
\hline & $\geq 2$ hours & $11(3 \%)$ & 15 & \\
\hline \multirow[t]{5}{*}{ The main target of gym use } & Body building & 76 & 46 & \multirow[t]{5}{*}{$<0.001$} \\
\hline & Weight loss & 6 & 80 & \\
\hline & Fitness & 10 & 127 & \\
\hline & Entertainment & 2 & 11 & \\
\hline & Medical cause mention it & 0 & 10 & \\
\hline \multirow[t]{3}{*}{ Qualified trainers in the gym } & Yes & 42 & 66 & \multirow[t]{3}{*}{ NS* } \\
\hline & No & 39 & 170 & \\
\hline & I don't know & 8 & 38 & \\
\hline
\end{tabular}

\section{Discussion}

This study estimated the prevalence of Anabolic Androgenic Steroids (AAS) use among male gymnasts in the western province of Riyadh city during 2017. The associating factors leading to AAS use and the level of awareness 
and knowledge of the potential side effects of AAS consumption also have been assessed. In this study, the frequency of AAS users was $24.50 \%$. This percentage is less than that reported in a similar study done by Jabari M. et al. and showed that the prevalence of AAS use amongst athletes in Riyadh is $30.50 \%(21)$. Moreover, it is lower than that in western Iran which estimated that the frequency of AAS abuse was $28.8 \%$ among body builders (16) and in between average of the studies that were done in Kuwait (22.77\%), UAE (22\%) and Jordan (26\%) (13-15). When compared internationally, it is more than that reported in the USA (20\%), less than the South Wales prevalence $(70 \%)$ and falls within the range of AAS use in Brazil (2.1-31.6\%) (9-11). More than half of the participant gymnasts (59\%) were in the age group of 18-25 years, however, the majority of AAS users (54\%) belong to the age group of 26-33 years $(\mathrm{p}=0.023)$, which is consistent with that reported in a similar study done in Kuwait by Alsaeed I and Alabkal J., and showed that most AAS users belong to age group $(25-29)$. It is also consistent with that which was reported in a Jordanian study done by Tahtamouni LH1, Mustafa NH, Alfaouri AA, Hassan IM, Abdalla MY, Yasin SR. and showed that the mean age of AAS users was 28 years. The results showed that there was a statistically significant inverse relationship between use of AAS and level of education $(\mathrm{p}=0.009)$ which is against what was reported in the UAE in the study of Omar Al-Falasi, Khalid Al-Dahmani, Khalid Al-Eisaei, Salem AlAmeri, Fatma Al-Maskari, Nicholas Nagelkerke and John Schneider, and showed that AAS users had a lower level of education than non-users. It is likely that, most of the individuals with lower levels of education have no idea about AAS and only want to use gyms for fitness purposes while the better-educated ones may utilize AAS for body building. This may also indicate that a desire of having a muscular appearance may also be strongly influenced by level of education. Surprisingly, most of the AAS users were married (59\%) although the majority of the participants were single (56\%), which may be due to wives influence or to increase sexual drive ability, although the latter was the target of few of the users (3.3\%)and could be explained by what was reported in a similar survey done on 4,000 Swedish male adolescents by Nilsson S1, Spak F, Marklund B, Baigi A, Allebeck P. and documented that most of AAS users believed that females preferred males with large muscles. In another variable, $67 \%$ of AAS users had a monthly income in the range 6000-12000 Saudi Riyal, while 55\% of non-users had a monthly income less than 6000 Saudi Riyal $(\mathrm{p}<0.001)$. As a result, rising incomes are contributing to AAS use because of their high price. Also, this is supporting the result that shows that $73 \%$ of users were employees, either governmental or private, whereas $10 \%$ of the users were students. That is similar what was reported in the Jordanian study by Tahtamouni LH1, Mustafa NH, Alfaouri AA, Hassan IM, Abdalla MY and Yasin SR, and showed that most AAS users were employed and had more income than non-users. The study showed that $62.3 \%$ of gymnasts who were targeting body building were AAS users. So, this confirms that body builders are more vulnerable to AAS use $(\mathrm{p}=0.004)$. The presence of qualified trainers in the gyms did not seem to make a difference in AAS use or non-use. Through this study, we found that most AAS types such as Testosterone, Methandrostenolone, and Stanozolol were available in Saudi Arabia through illegal ways, especially online shopping through the internet, which has a large number of electronic stores that are not licensed and not controlled, as well as the gym trainers who promote the use of AAS. Furthermore, it is of concern that even though AAS are illegal in Saudi, 7.8\% of AAS users reported being able to acquire AAS from pharmacists and physicians who are knowledgeable regarding the risks of taking AAS. Seventynine percent of participants in this study had an inadequate perception of AAS, and $84 \%$ of them had inadequate knowledge of its adverse effects with no significant difference between AAS users and non-users $(\mathrm{p}=0.24)$. This reflects the low level of awareness about AAS and that expected as shown in a similar study in Riyadh by Jabari M, Al-shehri Hassan, Al-faris Abdullah et al, 2015 and also in multiple regional studies done in neighboring countries like Kuwait which showed that $50 \%$ of users had inadequate knowledge, with no significant difference between users and non-users. Internationally, the survey which was done on Swedish adolescents reported that fewer AAS users believed AAS to be harmful. The low level of awareness about AAS in Saudi Arabia may be for several reasons including the media's lack of awareness-raising messages to the community. It may be due to the disregard of doctors and health professionals to alert this phenomenon and cooperate with other government institutions to increase the level of awareness and control of these substances, in addition to the role of schools that are supposed to include sports and physical health issues within their curricula. Regarding the strength and limitations of the study we should say that the research was a descriptive and analytic cross-sectional study. This design was chosen as it is the best suited to investigate the prevalence of AAS use. A survey of this nature does have a limitation, the gymnasts who have been asked to report their use of prohibited substance were expected to underreport such use. To avoid this potential, an online survey via the internet was used, and confidentiality was assured, and participants were asked to complete the questionnaire anonymously. In this study, female gyms were excluded due to inability to reach them because of social and religious reasons. Also, the governmental sports clubs were excluded because they are under the control of SAADC which would include investigations and punishments. 


\section{Conclusions}

Our study reveals the high prevalence of AAS amongst gymnasts in the western province of Riyadh city. However, this might be higher due to the possibility of underreporting from some gymnasts because of the sensitivity of the subject. Testosterone was the most common AAS type used by users. In addition, online shopping through the internet was the major source for obtaining AAS followed by gym coaches. Regarding the level of awareness, it was shown to be low among AAS users and non-users either toward AAS concept or its adverse effects. The percentage of AAS use is likely to increase if there are no educational programs established to increase public awareness and help to avoid the propagation of AAS usage in the future. The study also showed that, not surprisingly, gymnasts are at high risk of AAS use and therefore represent a suitable target group for AAS prevention with gyms as a natural area for these activities, which is worth noting when forming future AAS prevention methods. Also, we recommend the responsible authorities to tighten control over online-shopping via the internet and over the fitness centers. Finally, more studies are required to assess health care workers' knowledge toward AAS.

\section{Acknowledgments:}

We gratefully acknowledge the helpful validation of our study questionnaire by Dr. Tarik Al Said (consultant of family medicine), Dr. Mohammed Bardi (consultant of Psychiatry and substance abuse) and Dr. Vittorrio Fineschi (professor of legal medicine).

\section{Conflict of Interest:}

There is no conflict of interest to be declared.

\section{Authors' contributions:}

Both authors contributed to this project and article equally. Both authors read and approved the final manuscript.

\section{References:}

1) Evans NA. Current concepts in anabolic-androgenic steroids. Am J Sports Med. 2004; 32(2): 534-42. doi: 10.1177/0363546503262202. PMID: 14977687.

2) Kishner S. Anabolic Steroid Use and Abuse. Medscape website. 2015.

3) Parkinson AB, Evans NA. Anabolic androgenic steroids: a survey of 500 users. Med Sci Sports Exerc. 2006; 38(4): 644-51. doi: 10.1249/01.mss.0000210194.56834.5d. PMID: 16679978.

4) Hartgens F, Kuipers H. Effects of androgenic-anabolic steroids in athletes. Sports Med. 2004; 34(8): 513 54. doi: 10.2165/00007256-200434080-00003.

5) Dodge $T$, Hoagland $M$. The use of anabolic androgenic steroids and polypharmacy: a review of the literature. Drug Alcohol Depend. 2011; 114(2-3): 100-9. doi: 10.1016/j.drugalcdep.2010.11.011. PMID: 21232881, PMCID: PMC3062678.

6) Volkow ND. Anabolic Steroid Abuse. National institute on Drug Abuse; National Institutes of Health; U.S Department of Health and Human Services. Printed July 2001, Revised August 2006. 06-3721.

7) World Anti-Doping Agency. The World Anti-Doping Code Prohibited List. 2017. Available from: https://www.wada-ama.org/en/prohibited-list.

8) The Saudi Arabia Anti-Doping Committee. 2015. Available from: http://saadc.com/en/

9) Hall RC, Hall RC. Abuse of supraphysiologic doses of anabolic steroids. South Med J. 2005; 98(5): 550-5. doi: 10.1097/01.SMJ.0000157531.04472.B2. PMID: 15954512.

10) Baker JS, Graham MR, Davies B. Steroid and prescription medicine abuse in the health and fitness community: A regional study. Eur J Intern Med. 2006; 17(7): 479-84. doi: 10.1016/j.ejim.2006.04.010. PMID: 17098591.

11) Abrahin OS, Sousa EC, Santos AM. Prevalence of the use of anabolic-androgenic steroids in Brazil: a systematic review. Subst Use Misuse. 2014; 49(9): 1156-62. doi: 10.3109/10826084.2014.903750. doi: 10.3109/10826084.2014.903750.

12) Woerdeman J, de Hon O, Levi M, de Ronde WP. Anabolic androgenic steroids in amateur sports in the Netherlands. Ned Tijdschr Geneeskd. 2010; 154: A2004. PMID: 20858322.

13) Alsaeed I, Alabkal J. Usage and perceptions of anabolic-androgenic steroids among male fitness center attendees in Kuwait--a cross-sectional study. Subst Abuse Treat Prev Policy. 2015; 10(1). doi: 10.1186/s13011-015-0030-5. PMID: 26296560, PMCID: PMC4546264.

14) Al-Falasi O, Al-Dahmani KH, Al-Eisaei KH, Al-Ameri S, Al-Maskari F, Nagelkerke N, et al. Knowledge, Attitude, and Practice of Anabolic Steroids Use Among Gym Users in Al-Ain District, United Arab Emirates. The Open Sports Medicine Journal. 2008; 2: 75-81. doi: 10.2174/1874387000802010075. 
15) Tahtamouni LH, Mustafa NH, Alfaouri AA, Hassan IM, Abdalla MY, Yasin SR. Prevalence and risk factors for anabolic-androgenic steroid abuse among Jordanian collegiate students and athletes. Eur $\mathrm{J}$ Public Health. 2008; 18(6): 661-5. doi: 10.1093/eurpub/ckn062. PMID: 18603598.

16) Razavi Z, Moeini B, Shafiei Y, Bazmamoun H. Prevalence of anabolic steroid use and associated factors among body-builders in Hamadan, West province of Iran. J Res Health Sci. 2014; 14(2): 163-6. PMID: 24728754.

17) Nilsson S, Spak F, Marklund B, Baigi A, Allebeck P. Attitudes and behaviors with regards to androgenic anabolic steroids among male adolescents in a county of Sweden. Subst Use Misuse. 2004; 39(8): 1183-97. doi: 10.1081/JA-120030060. PMID: 15461017.

18) Fayyazi Bordbar MR, Abdollahian E, Samadi R, Dolatabadi H. Frequency of use, awareness, and attitudes toward side effects of anabolic-androgenic steroids consumption among male medical students in Iran. Subst Use Misuse. 2014; 49(13): 1751-8. doi: 10.3109/10826084.2014.880175. PMID: 25026387.

19) Al Ghobain M, Konbaz MS, Almassad A, Alsultan A, Al Shubaili M, AlShabanh O. Prevalence, knowledge and attitude of prohibited substances use (doping) among Saudi sports players. Substance Abuse Treatment, Prevention, and Policy. 2016; 11: 14. doi: 10.1186/s13011-016-0058-1.

20) Al Romaih F. Prevalence of use of performance enhancing drugs by adult fitness center members in Riyadh. 2016.

21) Jabari M, Al-Shehri H, Al-Faris A, Al-Sayed M, Algaeed F, Al-Sobaie N, et al. The prevalence of anabolic androgenic steroid use amongst athletes in Riyadh (Saudi Arabia). Electron Physician. 2016; 8(12): 3343-7. doi: 10.19082/3343. PMID: 28163846, PMCID: PMC5279964. 